\title{
Editorial
}

\section{Measuring, counting, interpreting: Our debate on methods continues}

American Journal of Cultural Sociology (2015) 3, 309-310. doi:10.1057/ajcs.2015.13

Why can't cultural sociology be a science? Or can it? And should it? These are the questions that animate an ongoing debate in the American Journal of Cultural Sociology, which reaches an unprecedented level of theoretical sophistication and civil animation in the present issue.

This debate began a decade ago with the inaugural conference of Yale's Center for Cultural Sociology. Contributing to one of the volumes of collected papers Isaac Reed and I edited from the conference, Meaning and Method (2009), Richard Biernacki seized the opportunity to present a fierce but systematic attack on coding as a method of textual analysis, a 90-page polemic to which John Evans offered a spirited reply and Biernacki answered in turn. Elaborating his argument theoretically and expanding it empirically, Biernacki subsequently published Reinventing Evidence in Social Inquiry (2012), which, along with Reed's Interpretation and Social Knowledge (2011), launched a new Methodenstreit in American interpretive sociology, and beyond. These works constitute the most significant social scientific discussions of cultural method in decades, building upon and going well beyond the foundational arguments of Weber and Dilthey, providing the social science equivalent to what Hans Georg Gadamer did for hermeneutics in philosophy four decades ago.

Biernacki defended subjectivity in cultural interpretation. Highlighting the extraordinary resource that a social scientist's cultural sensibility provides, he justified the interpretive idiosyncrasies that ineluctably affect investigations into and generalizations about social meanings - however rigorous personal and disciplinary commitments to value neutrality and evidence. Biernacki is not against counting; understanding and explaining meaning can be enhanced by measurement. What he warns against is the wishful thinking that counting, and coding in particular, can substitute for - or, as he sees it, try to render invisible - the necessary subjectivity of interpretation.

This is exactly the point at which Monica Lee and John Levi Martin take aim in their opening salvo, 'Coding, Counting, and Cultural Cartography,' 
published in the Issue 3.1 (2015) of AJCS. What particularly set apart this argument for quantitative method in cultural analysis was Lee and Martin's acceptance of Biernacki's controversial critique of coding, even as they went on to argue for a deeper level of computation, one that, following the digital humanities, tries to quantify the fundaments of meaning itself. What Biernacki replies to these 'frenemies' holds pride of place in the current issue, but extensive comments on Lee and Martin also follow from Isaac Reed and Lyn Spillman, themselves theorists and practitioners of cultural-sociological methods at the highest level. Lee and Martin reprise.

La lutte continue!

Jeffrey C. Alexander Co-Editor 